\title{
Exploring the MaaS market with systematic analysis
}

\author{
Domokos Esztergár-Kiss ${ }^{*} \mathbb{D}$, Tamás Kerényi, Tamás Mátrai and Attila Aba
}

\begin{abstract}
Mobility as a Service (MaaS) is a new transport concept which integrates, manages, and distributes private and public mobility alternatives by using intelligent digital technologies. Recently, research and implementations have been widely conducted. In order to reveal future implications, it is crucial to analyze the available Maas services by using systematic methodology. Cluster analysis was applied to create typical groups of MaaS services and to define the common features of the systems, which may highlight future trends. In order to identify the most relevant MaaS initiatives, the typical parameters of the services were taken into account and a dataset was developed. More than 30 MaaS services from 14 countries were investigated, and the features and the functionalities of these services were analyzed. The findings demonstrate that there is potential for the development of the applications in terms of their payment features, their personalization, and the provision of all attainable elements of Maas. The number of operators is constantly increasing. However, it is uncertain whether public or private MaaS operators will be dominant on the market. Three cluster groups were created with specific features and directions of development. The Route planners group involves a few modes of transport, but it provides an extensive service. While the Third parties group has primarily private MaaS operators, the Public systems group usually includes public MaaS operators. This comprehensive study might be useful to MaaS operators and regulators for understanding the typical features and the development directions of the market.
\end{abstract}

Keywords: Mobility as a service, Market structure, Applications, Cluster analysis, Business models

\section{Introduction}

Mobility as a Service (MaaS) is a new transport concept which integrates, manages, and distributes private and public mobility alternatives by using intelligent digital technologies. MaaS also integrates services, which are usually separately managed, such as planning, booking, payment, and ticketing to a single interface. MaaS aims to bridge the gap between public and private transport operators at urban and national levels [13].

MaaS is a widely discussed topic and applications applying the MaaS scheme are appearing all around the world with various functionalities. However, in the research field, there is a lack of comprehensive research, which collects and compares existing solutions in such a

\footnotetext{
* Correspondence: esztergar@mail.bme.hu

Department of Transport Technology and Economics, Budapest University of Technology and Economics, Múegyetem rkp 3, Budapest 1111, Hungary
}

way that the functionalities might be evaluated and clustered. Therefore, this study aims to provide an overview of the MaaS market through an analysis of available MaaS solutions, where the applications and their functions and features are assessed in a systematic way, and a clustering is realized to compare features of similar solutions.

After a short introduction, in section 2, the background of MaaS services is provided. Thus, the section includes the definitions of MaaS related terms, an overview of the structure of the MaaS market by introducing the main stakeholders. Moreover, the development of MaaS services, some related projects with realized MaaS solutions, and the relevant literature considering the MaaS concept and possible categorizations are presented in section 2. Section 3 deals with the method of the systematic analysis. This section explains the considered parameters and introduces the applied cluster analysis. 
In Section 4, the results are presented by a descriptive analysis, followed by the integration levels, the penetration, the regional differences, the operator features, the service platform, and other features, and finally, the cluster analysis. Section 5 is dedicated to the discussion of MaaS business models with specific examples, the limitations of the study and the future research opportunities. Section 6 provides the conclusion, which summarizes the research.

\section{Background}

\subsection{Definitions}

The first definition of MaaS, which was presented by Hietanen [7], states that it is a "mobility distribution model in which a customer's major transportation needs are met over one interface and are offered by a service provider." MaaS Alliance [18] defines a MaaS service as an operator which brings new business models, organizes, and operates various transport options for the benefit of users and operators. Another definition of the MaaS concept declares that "Mobility as a Service is a user-centric, intelligent mobility management and distribution system, in which an integrator brings together offerings of multiple mobility service providers, and provides end-users access to them through a digital interface, allowing them to seamlessly plan and pay for mobility" [14]. This is the definition, which is applied in this research to assess whether an application provides real MaaS services or not. A MaaS operator "facilitates a diverse menu of transport options, be they public transport, ride-, car- or bike-sharing, taxi or car rental/lease, or a combination thereof" [18].

When developing or implementing advanced mobility services, first of all, the key elements have to be defined [3]. Moreover, the major trends of the development have to be explored [11]. Accessibility is one of the most important features of transportation systems. A system can be more attractive by providing door-to-door-mobility and sustainable transportation services [27]. It is expected that MaaS services start operating in urban areas, and the role of public transport providers are emphasized. Furthermore, the organizational and technological enablers of MaaS and the elements which support the realization of pilots have to be described [21]. More precisely, the implementation of MaaS has to be investigated based on such characteristics as regulation, infrastructure, services, operators, and citizens [4].

\subsection{MaaS market structure}

As part of the theoretical background, a short description of the actors on MaaS market is provided in this subsection. This paper concentrates on the MaaS operators and their services whose data are publicly available and quite reliable. Besides MaaS operators, Mobility
Service Providers (MSPs) and the users play the most crucial roles since they are involved in the core business of the MaaS business ecosystem [12]. However, on the market, there are several other stakeholders, who play significant roles in the market development. Data providers, infrastructure providers, regulators, public authorities, and third party aggregators are part of the ecosystem as they support the cooperation and the sharing of the relevant data among the stakeholders [34].

Figure 1 shows the changing demand and the supply relationship in MaaS business ecosystem, where the green represents the new relations occurring with the appearance of MaaS services on the market. In Fig. 1, the orange sign illustrates the classical mobility market relations. Considering this, a major part of this paper is dedicated to the analysis of Mobility Service Operators (MSOs). However, the growth of the MaaS market might depend on MSPs and the users, too. The role of both public and private actors and their business relationships were studied. MSPs vary substantially by their interest in the market: some of them have similar goals (such as car-sharing services), while others see MSOs as potential competitors since they have a direct connection with the users [31].

\subsection{Related projects}

In 2011, the International Association of Public Transport (UITP) predicted that some specific modes of transport, such as car-sharing, taxi, shared taxi, bicycle, or bike-sharing, could complement classical public transport [36]. At the 10th European Congress, in Helsinki, the MaaS concept, which included mobility packages as a subscription service to users, was presented. In 2015, a start-up company, which provided mobility packages, launched the Whim mobile application in Helsinki. After a year, they started to distribute the service in other locations [2].

As MaaS is a new paradigm and has the potential to solve transportation related problems, research about the topic was realized in the form of several projects, which primarily focused on the providing of advanced mobility services and the introduction of pilots (Table 1). These MaaS projects are of great importance for the development of MaaS frameworks as these projects provide opportunities to test open platforms and business plans as well as give insights into the direction of the MaaS market development. In some cases, the location referred to a national implementation (e.g. Austria, Scotland), while in other cases specific cities were in the focus of the pilot (e.g. Gothenburg, Copenhagen).

Ubigo [35] was the result of a national project which aimed to support the residents of Gothenburg, Sweden to travel in a smarter and more sustainable way. In this project an innovative travel service UbiGo was developed 


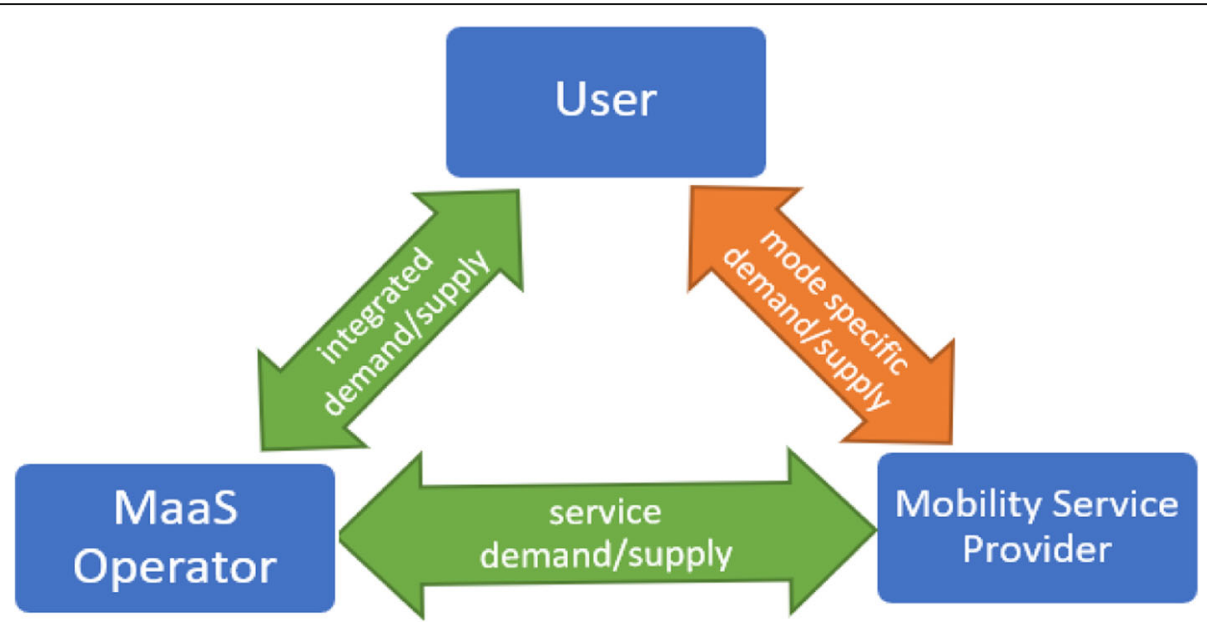

Fig. 1 Changing relations on the MaaS market

and tested. The service provided tailor made mobility packages suited for combining various transport services, such as public transport, taxi, electric car pooling, or bike pooling [8].

Smile project [30] was funded by the Austrian Federal Government. The goal of this project was to create a mobility platform where travelers were informed of all available means of transport, and they could book, pay, and access the services. The integrated mobility platform in form of a smartphone app was tested by over 1000 pilot users in several cities of Austria.

MAASiFiE [20] was a synthesis research project financed by the CEDR Transnational Road Research Program 2014 on Mobility and ITS. The main focus of MAASiFiE was to identify and analyze the MaaS models and to create the 2025 roadmap for Europe. Another aims was to develop business models and to persuade public and private stakeholders to join the initiative.

The main objective of the New Mobility project [24] was to offer the residents of Copenhagen an opportunity to test mobility packages. The "Mobility Pack" service package aimed to provide all the transport needs of a person or a family with moderate car use. Instead of the car, transport services like city bikes, city cars, carsharing, car rental, or public transport were offered. Due to the mobility package, more travelers could experience the latest e-bikes and electric vehicles; at the same time, the freedom to choose among the modes was provided.

The Pick\&Mix project [25] in Scotland aimed to develop MaaS applications for youngsters. The project brought together all the available transport options offering discounts for students and people under 18 and provided optimized transport alternatives. This app was designed and it was used by a selected group of youngsters. Thus, the app reflected the young people's needs and perceptions of each service and transport modes with an aim to minimize private car use and ownership.

The IMOVE project [9] was funded by the Horizon 2020 programme for research and innovation. The project's aim was to accelerate the deployment of MaaS services and to unlock the scalability of MaaS schemes in Europe, thus paving the way for the development of a roaming service for MaaS users across various European countries. Although a few MaaS initiatives have already

Table 1 Main features of the MaaS project sample

\begin{tabular}{|c|c|c|c|}
\hline Project name & Project period & Pilot location & Main objective \\
\hline Ubigo & January 2012 - December 2014 & Gothenburg & test an innovative travel service \\
\hline Smile & June 2012 - May 2015 & Vienna & $\begin{array}{l}\text { develop a prototype of an integrated mobility } \\
\text { platform }\end{array}$ \\
\hline MAASiFiE & June 2015 - May 2017 & - & create a MaaS roadmap \\
\hline New Mobility & April 2017 - June 2017 & Copenhagen & test mobility packages \\
\hline Pick\&Mix & June 2017 - May 2018 & Scotland & develop an application for young people \\
\hline IMOVE & June 2017 - Nov 2019 & Berlin, Gothenburg, Manchester, Turin & investigate the scalability of MaaS schemes \\
\hline MyCorridor & June 2017 - May 2020 & Amsterdam, Athens, Rome, Prague, Salzburg & offer tailored mobility solutions \\
\hline MaaS4 & June 2017 - May 2020 & Manchester, Luxembourg, Budapest & provide frameworks and tools for the MaaS concep \\
\hline
\end{tabular}


been piloted in Europe, most of them did not obtain a significant scale and a stable business operation level. IMOVE addressed the main challenges of MaaS development by investigating the innovative business and the technology enablers of advanced solutions parallelly and by validating the designed solutions of four European living labs, namely Berlin, Gothenburg, Greater Manchester, and Turin.

The MyCorridor project [23] aimed to facilitate sustainable travel in urban and regional areas as well as across borders by replacing vehicle ownership with vehicle usage. The project's objective was to put users at the core of transport services by using MaaS and to offer travelers tailored mobility solutions based on their individual needs. The project created a unified mobility platform, which was accessible via a single app. The pilots were realized in several cities, such as Amsterdam, Athens, Prague, Rome, and Salzburg.

The MaaS4 project [19] provided quantifiable evidence, frameworks, and tools which aided to remove the barriers and to facilitate a cooperative and interconnected EU single transport market for the MaaS concept. The aim of the project was achieved by defining sustainable business models that supported the cooperation across transport stakeholders, by understanding user needs and choices, by implementing the required technological infrastructure (a MaaS mobility hub), and by identifying the enabling policy and the regulatory frameworks. The project demonstrated the concept for urban, intercity, and cross-border trips in three European countries by providing a cost and benefit analysis for three complementary pilot cases (i.e. the United Kingdom, LuxemburgGermany, Hungary).

These projects explored different technical, operational, regulation, and business options to encourage MaaS operators to develop such transport services which might be beneficial for the users and the service operators, too.

\subsection{Relevant research}

The research about MaaS solutions started around 2016, and since then, the relevant literature has been growing continuously. Utriainen and Pöllänen [38] collected $\mathrm{MaaS}$ related literature and categorized them into three groups, i.e. the role of transportation modes, the pilot findings, and the expected effects. However, no classification of the available MaaS applications was conducted. Sochor et al. [33] identified the key aspects which characterized MaaS services. They included societal, business, user, and technical perspectives. The main aspects of the study covered the type of information, the booking, the ticketing, the payment, the responsibility, the pricing models, the number of services; however, the solutions were neither evaluated nor clustered. Sarasini et al. [28] focused on the business models of MaaS solutions primarily by considering the economic, the environmental, and the social dimensions of sustainability. The researchers classified MaaS business models based on mobility services, data services, resource efficiency, and environmentally friendliness, but the user services were not brought into focus.

A more user-focused study is demonstrated by Arnaoutaki et al. [1]. The researchers dealt with the designing and offering of viable MaaS products including a suggestion for an optimal MaaS plan that matches the personal needs of the user. The outcome is a filtered and ranked list of MaaS mobility packages, however in this case, only the packages were in the focus rather than all services related to the user experience. Schikofsky et al. [29] categorized motivational factors, such as efficiency and performance, the ease of use, the choices based on preferences, the feeling of control, and the anticipated enjoyment. The research primarily focused on the behavioral intention to adopt MaaS offerings, but not genuinely on the technical features of Maas applications.

Other researchers dealt with MaaS solutions and classification opportunities. The paper of Jittrapirom et al. [10] defined a set of attributes that were applied to describe the selected MaaS schemes and existing applications. The core characteristics were the integration of transport modes, the tariff options, the platform, the actors, the use of technologies, the demand orientation, the registration requirements, the personalization, and the customization. The researchers analyzed several applications and highlighted best practices but without defining the specific levels of integration. Hensher et al. [6] focused on MaaS schemes. The scholars listed available services based on their status, their introduction date, the number of transportation modes and the level of integration. Moreover, the researchers provided a general comparison related to payment integration and service offers. This approach is the closest to the current paper's, however it did not consider several technical aspects and features of the MaaS applications, which are relevant to assess the applications in a systematic way.

Considering clustering opportunities more specifically, in the paper of Kamargianni et al. [12], existing MaaS schemes were reviewed, and an index was developed to evaluate the level of mobility integration and the number of transport services for each MaaS application. The index included three main elements, which were the following: Ticket and Payment integration, Mobility packages, and Information and Communication Technologies (ICT) integration. ICT integration usually contains the connection between travel information services. Ticketing and payment integration are usually achieved by the introduction and development of smart card technologies. The 
systems of smart cards came into existence a few decades ago. The integration of mobility packages provided a real advanced step in the development of MaaS functionalities, however the paper does not consider all aspects of MaaS services.

A more systematic approach was adopted by Sochor et al. [32], who aimed to facilitate the comparison of different services and to understand potential effects. Based on an analysis of the existing definitions and the expert workshop, the researchers identified key aspects and integration levels.

Based on the listed literature reviews, it seems that on the analysis of MaaS applications on the market, there is a lack of comprehensive research which would evaluate MaaS services based on a predefined set of parameters by using a systematic approach and cluster analysis as well as taking into account the market penetration and other relevant functionalities.

Thus, considering the new paradigm of the MaaS concept, the changing status of the market, and the new applications and projects appearing, there is a need to tackle the MaaS market in a more systematic way. Therefore, the aim of this paper is:

- to provide an overview of the sampled MaaS applications,

- to analyze the features and the functionalities of these services,

- to cluster the applications and to define the common features of these systems,

- to highlight future development directions through existing services.

\section{Method}

To define and provide an overview of the most relevant MaaS initiatives, a wide range of literature (e.g. [10, 12, 32]) and the service map of MaaS Alliance were used during the application search. If the applications were available to download, then they were tested, otherwise external information was used (e.g. reviews and forums). We defined the main aspects and created a list of parameters to assess the data. The parameters and their definitions are presented here.

\subsection{Basic data}

Some basic data of the services were listed, such as the introduction date of the service and the penetration rate. The introduction dates showed the year of the app's appearance in the Google Play store. The penetration represented the number of downloads from the Google Play store, which provided an approximate value for the application.

\subsection{Covered area}

First, the spatial features of the services were analyzed. The covered area was noted at a city and country level. Some applications operated nationwide; thus, in these cases, the area of the country was assigned. This part contained the potential service area in $\mathrm{km} 2$, where all functions of the service could be utilized.

\subsection{Status}

The status indicated the lifecycle phase of the application. Three service status types were defined: planned, operational, and terminated. The running and available applications were considered as operational. The terminated services were generally run as pilot systems (e.g. the Smile application was available only for a predefined period). The planned status type was labelled for those cases in which the applications were still in design, under development or not in a running stage yet. However, some information about the planned services on webpages could be identified.

\subsection{Platform}

The appearance of the service could be implemented in different ways: it could be a website, a mobile application, or a travel card. In case of the latter, the service was often connected to a website or a mobile application. Furthermore, it was possible to have a website and an app for the same service.

\subsection{Payment method}

In most cases, the payment method was pay-as-you-go, which meant that the traveler could directly pay once a service was used. Some services introduced a monthly account, where travelers could use the services and settle the invoice at the end of the month. Very few services realized mobility packages, which meant a mix of transport services, for a predefined price.

\subsection{Payment platform}

It defined how the payment could be realized. There were three options, i.e. web-based solutions, direct payment through the application, or using a physical card.

\subsection{Transport operator}

The transport operators, who provided their services to the MaaS, may have had two types: public or private. Typically, public transport and train operators were public actors, while car-sharing, car-rental, and ride-sharing operators were usually private actors.

\subsection{MaaS operator}

The MaaS ecosystem was built on the interactions of different groups of actors, such as users (e.g. private customer or business customer) and a supplier of transport 
services (e.g. public or private), through a digital platform. The MaaS operator could be a public transport service operator (PT provider), a local authority, or a third party (private company). The role of the operator was primarily to aggregate transport services and to provide them to the user through a single digital interface.

\subsection{MaaS service}

Two types were considered: real MaaS and self-defined MaaS. In the first category, those applications were included which were fully aligned with the definition of MaaS (as defined in the introduction section). In the second category, those applications appeared where the service itself mentioned the term "MaaS" on its website, however in terms of services, it did not entirely fulfill all MaaS functionalities.

\subsection{Integration level}

The level of integration was assessed based on a categorization. The services were assigned to four levels (level 1: the integration of information, level 2: booking and payment, level 3: service offers, level 4: societal goals).

\subsection{Map}

When assessing the functionality related to the map, the coverage of specific transportation modes was in focus. Usually, the stops, the access points, or the vehicles were shown on a map, in most cases, in real-time with GPS coordinates and additional information. These modes could be public transport, bike, bike-sharing, carsharing, car-rental, ridesharing, taxi, shared-taxi, train, long-distance bus, on-demand bus, flight, car, parking, or charging points. The latter referred to the charging point of electric vehicles, which served the increasing demand of this new mobility option.

\subsection{Routing solutions}

Applications that included route planning and usually used real-time information were considered as having a routing solution. The services provided alternative options between two locations depending on which modes were selected. These could be public transport, bike, bike-sharing, car-sharing, car-rental, ridesharing, taxi, shared-taxi, train, long-distance bus, on-demand bus, flight, car, or parking. In several cases, the routes provided similar results (e.g. car and taxi). The dataset of the applications included additional services for parking, which was useful once the planned routes were crowded.

\subsection{Booking solutions}

Booking was available in two ways: in smartphone applications and on web-based services. The first solution was when routes, which were planned by the service, were directly booked in the system (no external application was required). Another version was when services could be booked without route planning (taxi or car rental were typically such modes of transport). In most cases, booking needed routing, thus the services built on each other.

\subsection{Ticketing solutions}

An integrated ticket solution appeared when a smart card or ticket solution on the web/app (QR-code, NFC) could be used to access the transport modes. The modes of transport which accepted the smart card or provided the ticket through the app were marked in the dataset.

\subsection{Payment solutions}

If the payment was made directly through the application or through the travel card, it could be called payment integration. Typically, the application saved the bankcard data or connected to a payment service provider (e.g., PayPal). Any modes or services that could be paid via these two options were indicated in the dataset.

\subsection{Other services}

Some additional services which were primarily connected to the routing solutions and provided extra functionalities were assessed, too. These services allowed the personalization (stored trip, saved locations) and customization (preferences, preferable modes) of services as well as supplied information (service alerts, traffic information). If the application had a service alert, it was marked in the dataset. Stored trips were marked if the app stored previous searches. The optimization of travel plans according to individual preferences, such as time, cost, and the number of transfers was labeled as route planning preferences. Furthermore, preferable transportation modes could be chosen by travelers. Some services could provide information about the emerging traffic situations and closures, which was denoted as traffic information in the dataset.

The main information about the analyzed parameters was summarized in Table 2 including the parameter name, the value type, and the value range. These parameters were created to be used as a basis for a structured discussion, to analyze main trends and features, and to determine which systems provide real MaaS services.

Cluster analysis was used to create typical clusters of MaaS services and to define the common features of these systems, which may highlight future trends. In order to assess the clustering tendency, Hopkins statistics $(\mathrm{H})$ were applied to the dataset [15]. If the result of the $\mathrm{H}$ was close to 1 , it indicated that the data was highly clustered. If the value was lower, the dataset could 
Table 2 Description of the parameters

\begin{tabular}{|c|c|c|}
\hline Parameter name & Value type & Value range \\
\hline Basic data: introduction date & Year & $2000-2019$ \\
\hline Basic data: Penetration rate & Number of downloads & $0-100.000 .000$ \\
\hline Covered area & Area in $\mathrm{km} 2$ & $0-1.000 .000$ \\
\hline Status & planned, operational, terminated & discrete choice \\
\hline Platform & website, application, card & multiple choice \\
\hline Payment method & pay-as-you-go, monthly account, mobility package & discrete choice \\
\hline Payment platform & website, application, card & multiple choice \\
\hline Transport operator & public, private & multiple choice \\
\hline MaaS operator & public transport provider, local authority, third party & discrete choice \\
\hline MaaS service & real service, self-defined & multiple choice \\
\hline Integration level & information, booking and payment, service offer, societal goals & discrete choice \\
\hline Map & $\begin{array}{l}\text { public transport, bike, bike-sharing, car-sharing, car-rental, ridesharing, taxi, shared-taxi, } \\
\text { train, long-distance bus, on-demand bus, flight, car, parking, charging point }\end{array}$ & multiple choice \\
\hline Routing & $\begin{array}{l}\text { public transport, bike, bike-sharing, car-sharing, car-rental, ridesharing, taxi, shared-taxi, } \\
\text { train, long-distance bus, on-demand bus, flight, car, parking }\end{array}$ & multiple choice \\
\hline Booking & $\begin{array}{l}\text { bike-sharing, car-sharing, car-rental, ridesharing, taxi, shared-taxi, train, long-distance bus, } \\
\text { on-demand bus, flight, parking }\end{array}$ & multiple choice \\
\hline Payment & $\begin{array}{l}\text { public transport, bike-sharing, car-sharing, car-rental, ridesharing, taxi, shared-taxi, train, } \\
\text { long-distance bus, on-demand bus, flight, parking }\end{array}$ & multiple choice \\
\hline Ticketing & $\begin{array}{l}\text { public transport, bike-sharing, car-sharing, car-rental, ridesharing, taxi, shared-taxi, train, } \\
\text { long-distance bus, on-demand bus, flight, parking }\end{array}$ & multiple choice \\
\hline Other services & stored trip, saved locations, preferences, preferable modes, service alerts, traffic information & multiple choice \\
\hline
\end{tabular}

not be grouped, meaning that it was not possible to create clusters from the dataset.

In the next phase, the k-medoids algorithm was applied to create clusters from the dataset. This method belongs to the k-means clustering approaches. However, the most commonly applied method is the Partitioning Around Medoids (PAM) algorithm, which is based on the search of $\mathrm{k}$ representative medoids in the dataset and clusters the remaining dataset around them [17]. As this method does not use the mean values of the cluster, it is less sensitive to outliers.

In this research, validation statistics were applied, where the average silhouette width measured the separation between clusters [5]. It is a measure for assessing the fit of individual objects in the classification as well as the quality of clusters. This can be visualized by a silhouette plot, which shows the silhouette coefficient for each object and cluster. If the coefficient is close to 1 , the object is in the correct cluster, which means that the classification is well performed. If the coefficient is close to 0 , it indicates that the object is between two clusters, which means that based on the features of the object, it is fitting to both clusters. If the coefficient is close to -1 , then the object is in the wrong cluster.

Finally, Principal Component Analysis (PCA) was applied to reduce the number of aspects which were assigned to the MaaS applications [15]. PCA is a common approach to reduce the number of variables by obtaining a set of principal variables which can be better visualized. A cluster plot was applied to visualize the clusters with PCA in a two-dimensional space. The two axes provided an artificial scale for visualization purposes. The created clusters are demonstrated and they provide an opportunity to analyze the members of the clusters.

\section{Results}

To provide an overview of the MaaS market, a dataset was created based on an analysis of the downloadable applications and the usable web services that fitted into the context of MaaS (Table 3). The applications were collected in 2019 and their data were updated in August 2020 .

\subsection{Descriptive analysis}

The MaaS services were collected and analyzed based on their penetration (at least 100 downloads), their covered area (city, regional and international coverage), and other aspects (such as operator types). Only those applications were considered which had a significant number of users and which were real MaaS or self-defined MaaS services. Thus, the innovative public transport services were not listed if they did not consider themselves as MaaS providers. The search for applications was 
Table 3 List of MaaS services and their main features

\begin{tabular}{|c|c|c|c|c|c|c|}
\hline $\mathrm{Nr}$ & Application name & Abbrev. & Date & Area & Status & Penetration \\
\hline 1 & Shift & - & 2013 & USA & terminated & - \\
\hline 2 & Smile & - & 2014 & Austria & terminated & - \\
\hline 3 & Ubigo & - & 2013/19 & Sweden & operational & $500+$ \\
\hline 4 & Optimod & OpMo & 2012 & France & operational & $10.000+$ \\
\hline 5 & Compte Mobilité & CoMo & 2018 & France & operational & $5000+$ \\
\hline 6 & Moovizy & Mvzy & 2014 & France & operational & $50.000+$ \\
\hline 7 & TaM & TaM & 2016 & France & operational & $100.000+$ \\
\hline 8 & MobiPalma & $\mathrm{MoPa}$ & 2013 & Spain & operational & $100.000+$ \\
\hline 9 & RACC trips & RACC & 2018 & Spain & operational & $10.000+$ \\
\hline 10 & Whim & Whim & 2017 & Finland & operational & $100.000+$ \\
\hline 11 & My Cicero & $\mathrm{MyCi}$ & 2016 & Italy & operational & $500.000+$ \\
\hline 12 & Reach Now (Moovel) & Mvel & 2016 & Germany & operational & $500.000+$ \\
\hline 13 & kvv.mobil & Kvv & 2014 & Germany & operational & $100.000+$ \\
\hline 14 & VIA goMobile & ViaM & 2012 & USA & operational & $100.000+$ \\
\hline 15 & Qixxit & Qixt & 2017 & Germany & operational & $50.000+$ \\
\hline 16 & HW & $\mathrm{HW}$ & 2012 & Germany & operational & $1.000 .000+$ \\
\hline 17 & GVH Hannovermobil & GVH & 2012 & Germany & operational & $100.000+$ \\
\hline 18 & Leipzig mobil & LeMo & 2015 & Germany & operational & $50.000+$ \\
\hline 19 & Mobility Mixx & MoMx & 2014 & Netherlands & operational & $10.000+$ \\
\hline 20 & NS & NS & 2010 & Netherlands & operational & $5.000 .000+$ \\
\hline 21 & STM (Communauto/Bixi) & STM & 2014 & Canada & operational & $100.000+$ \\
\hline 22 & Tim & Tim & 2017 & Austria & operational & $100,000+$ \\
\hline 23 & WienMobil & WiMo & 2016 & Austria & operational & $500.000+$ \\
\hline 24 & Moovit & Movt & 2012 & EU & operational & $50.000 .000+$ \\
\hline 25 & PostBus & PBUS & 2016 & Switzerland & operational & $100.000+$ \\
\hline 26 & Choice & Choi & 2017 & New Zealand & operational & $5000+$ \\
\hline 27 & RideMate & RiMa & 2017 & New Zealand & operational & $5000+$ \\
\hline 28 & Trav.ly & Trav & 2018 & UK & operational & $1000+$ \\
\hline 29 & Urbi & Urbi & 2014 & EU & operational & $1000+$ \\
\hline 30 & Mozio & Mozi & 2017 & Wordwide & operational & $50.000+$ \\
\hline 31 & Umaji & Umaj & 2013 & Taiwan & operational & $10.000+$ \\
\hline
\end{tabular}

conducted internationally, considering several countries. The analysis was based on the downloaded applications, the web interfaces, and the data from the service provider's website. All collected applications and their functionalities were checked one-by-one in a comprehensive way. Altogether, more than 30 initiatives from 14 countries and regions were analyzed. The majority of the schemes were from Europe, and a few were from the United States, New Zealand, Canada, and Asia. A few pilot schemes were planned but cancelled before their operation could begin (Shift, Smile). Ubigo originally started in 2013, and it was terminated for a while, however it restarted operation again in 2019.
The first 10 years of MaaS market evolution is shown in Fig. 2. The number of operators is increasing by around four per year, and the number of new introductions is quite constant. Therefore, according to our sample, there is a linear market growth trend, which is somewhat limited compared to the market trends of other emerging technologies (e.g., public bike-sharing) [22]. Out of the apps, 10 were self-defined MaaS services, and four of them indeed provided the four elements: routing, booking, payment, and ticketing in one app.

\subsection{Integration levels}

Considering the service levels, in Fig. 3, the number of Maas applications which were assigned to the specific 


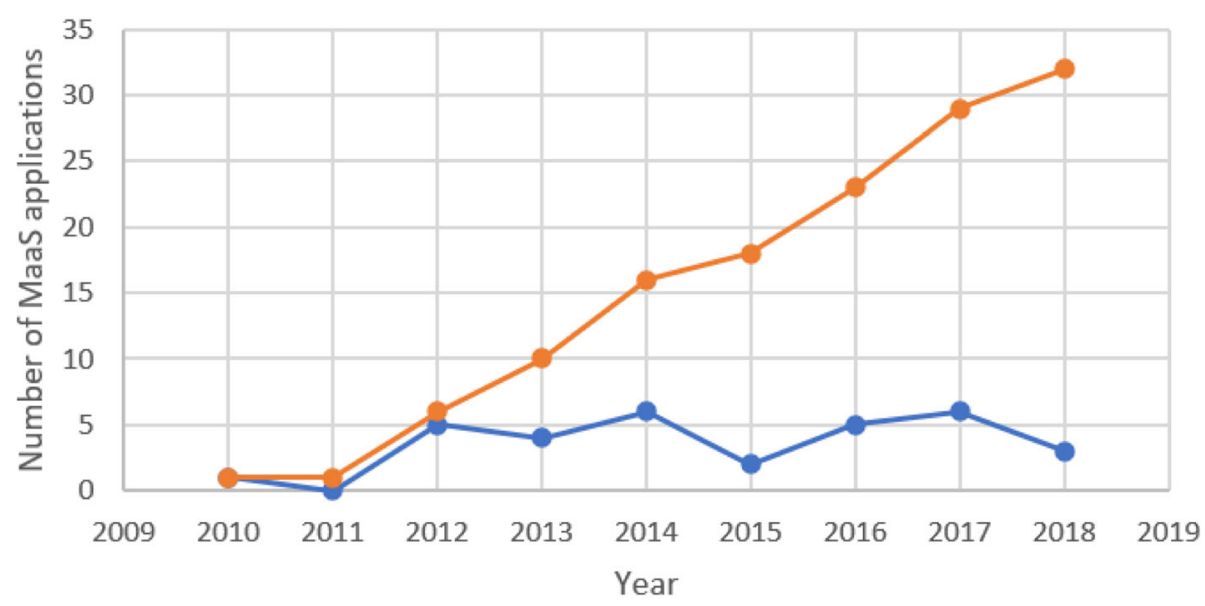

- Number of MaaS introductions per year - Number of available applications

Fig. 2 The number of MaaS applications in the market

integration levels are presented. It can be stated that every application reached level 1 , which meant that the information was provided in an integrated way. However, level 2 was assigned to less than $50 \%$ of the MaaS services, and level 3 was only realized in the case of Ubigo, Shift and Whim. Analyzing integration from another point of view, most MaaS services had some ICT related integration by providing advanced information services for the users. In terms of ticketing and payment, more than $50 \%$ of all applications had an integration to some extent. However, the fully integrated approach towards mobility packages was only realized in 3 cases.

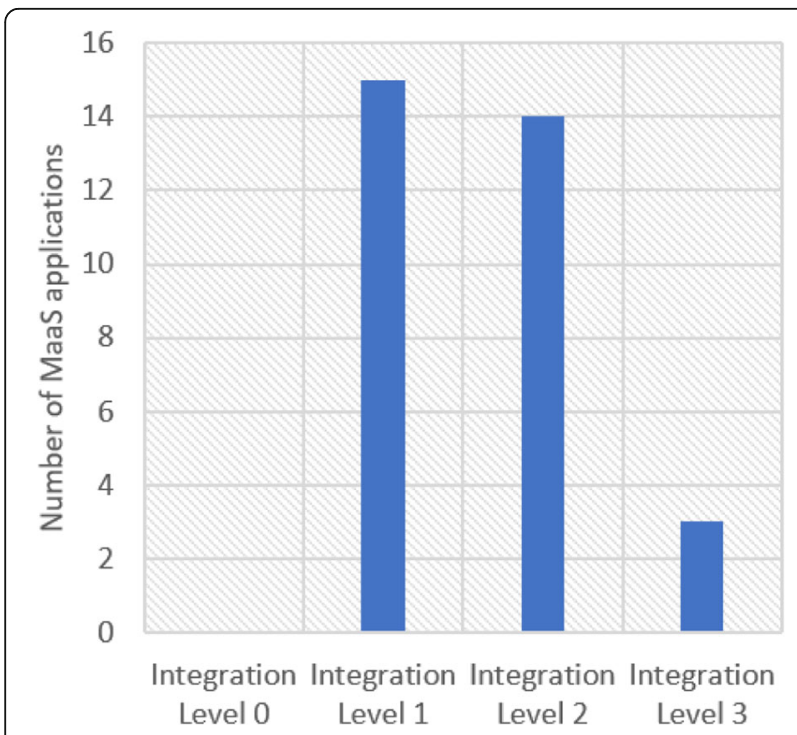

Fig. 3 Number of MaaS applications assigned to the integration levels

\subsection{Penetration}

The penetration of the applications could be deduced from the download numbers of the app stores. Figure 4 presents the download numbers of the Google Play application store. In addition to this, Fig. 4 gives an insight into the current penetration, too. A few MaaS applications had more than 1 million users, but the average download number was rather around 10,000.

\subsection{Covered area}

The Moovit application operated in the largest area. MyCicero (Italy), NS (Netherlands), Qixxit (Germany), and PostBus (Switzerland) arranged services at national levels, and these applications provided real-time planning, booking, ticketing, and payment. The backbone of these services was the national public transport systems (train, bus). Moovit had the largest number of downloads, which was followed by NS and HVV (Hamburg). In general, the area of MaaS operations were overlapping in a few cases; thus, competition was present but to a limited extent.

\subsection{Regional differences}

PT was the most frequently included transportation mode; $70 \%$ of the applications offered this mode. PostBus application handled the most modes of transport (PT, personal bike, bike-sharing, car-sharing, ridesharing, taxi, train, coach, and cable cars in the Alps). In the ranking, PostBus was followed by Whim, which included six modes. French and Spanish applications were characterized by the provision of many personalization and customization services, but booking, ticketing, and payment services were not provided. Austrian and German applications arranged many high-level public 


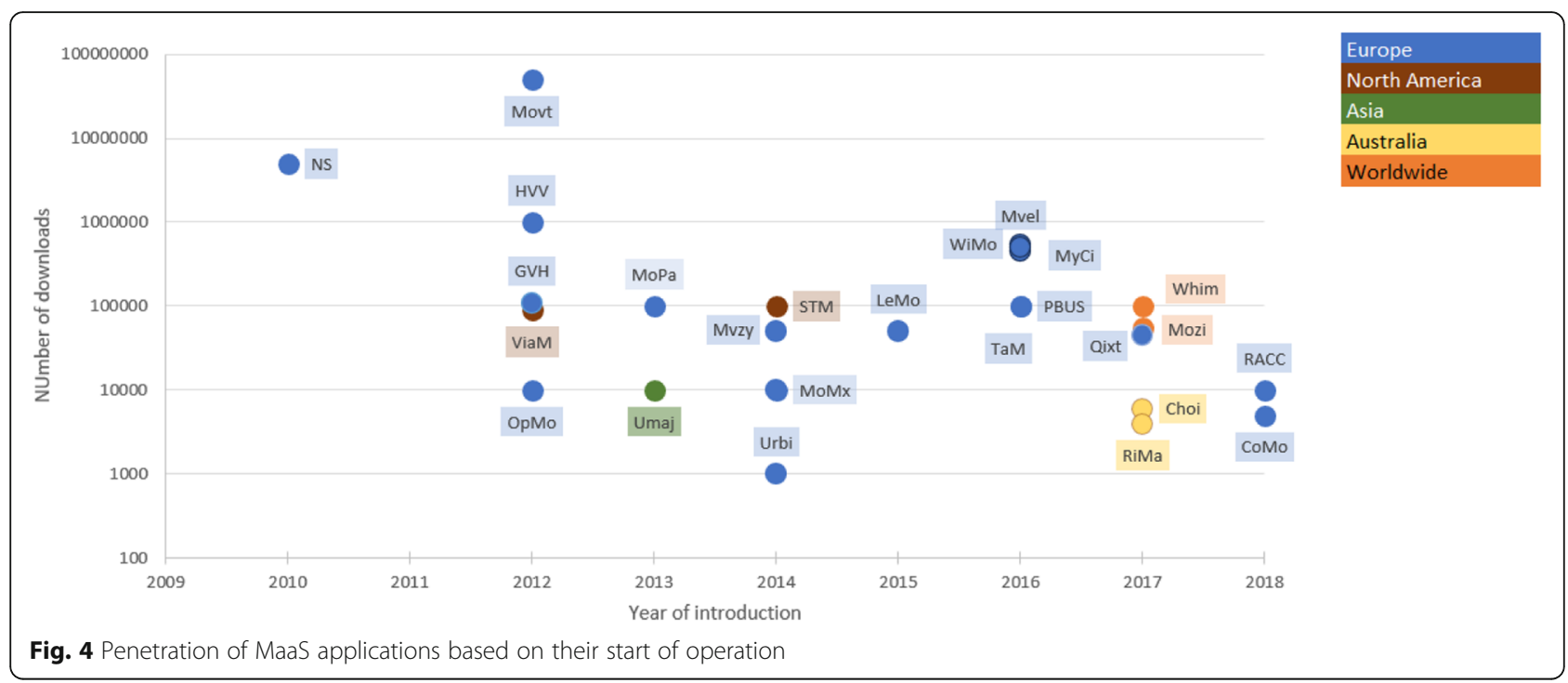

transport functions but mostly did not include other transportation modes.

\subsection{Operator features}

In Germany, Austria, and Switzerland, mostly a public transport operator developed the applications. Thus, they usually included public transport services (ticketing, payment). In France and Spain, the aggregators of the applications were predominantly the local authorities. Usually, third party services operated the applications in Scandinavian countries (UbiGo, Whim), outside Europe, and in case of international services. The aggregated distribution is shown in Fig. 5. The number of the public transport operator (32\%) and the local authority (25\%) was nearly the same, while the third party structure was the most common form (43\%).

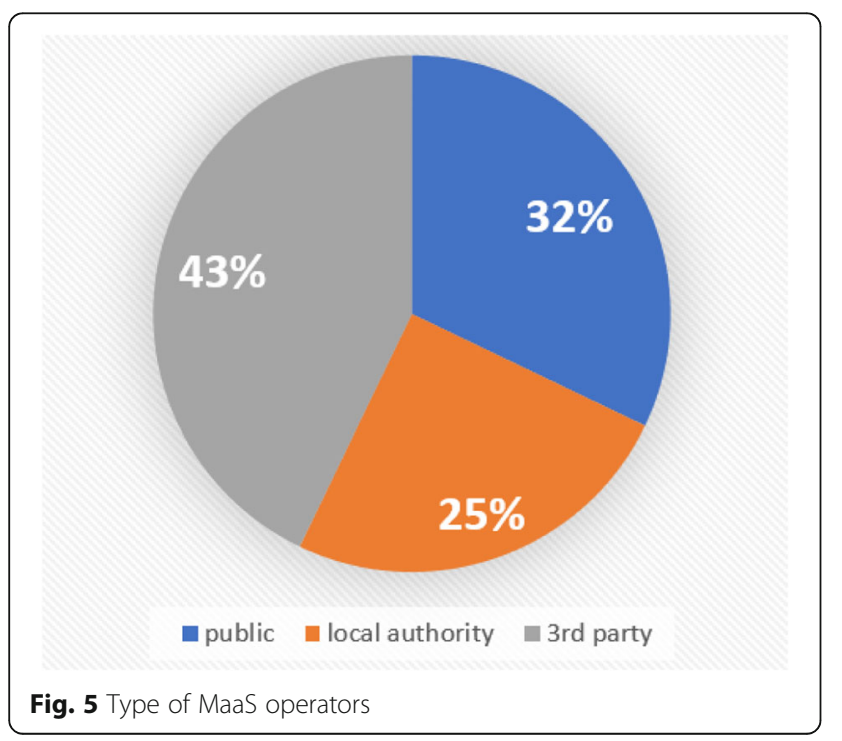

\subsection{Service platforms and other features}

The service platforms are presented in Fig. 6. Twenty seven services $(80 \%)$ were available for users via smartphone applications. Furthermore, almost half of the services were available solely through the application. There was not a service which was available exclusively on a web interface. There were a very few of applications which provided solely card-based options; however, combinations of these options with other platforms were more popular (reaching to $34 \%$ ).

Thirteen services $(53 \%)$ provided network information for users. These maps had routing information on all modes. Routing information was most often available in the service, where bike-sharing and car-sharing information was provided. Concerning booking, the taxi (47\%) and the car-sharing $(41 \%)$ modes were the most usual. A quarter of the services could offer reservation for any modes. As for ticketing, public transport was available in the two-thirds of the services.

Payment features were available in nine services (28\%), public transport was available for all applications except for the two private aggregator services. In one third of the applications with payment features, it was possible to pay for train, bike-sharing, car-sharing, and taxi.

According to Fig. 7, 77\% of the services offered one type of payment option (only app or only bank card). Payment through the application was more widespread compared to bank card payment. $15 \%$ of the services could have both app and bank card payment, and $65 \%$ of the payments could be processed online (using web or app).

Figure 8 shows the personalization and customization opportunities which were provided as settings by the application to the users. Three of the settings appeared in a high number of MaaS applications, i.e. preferable 


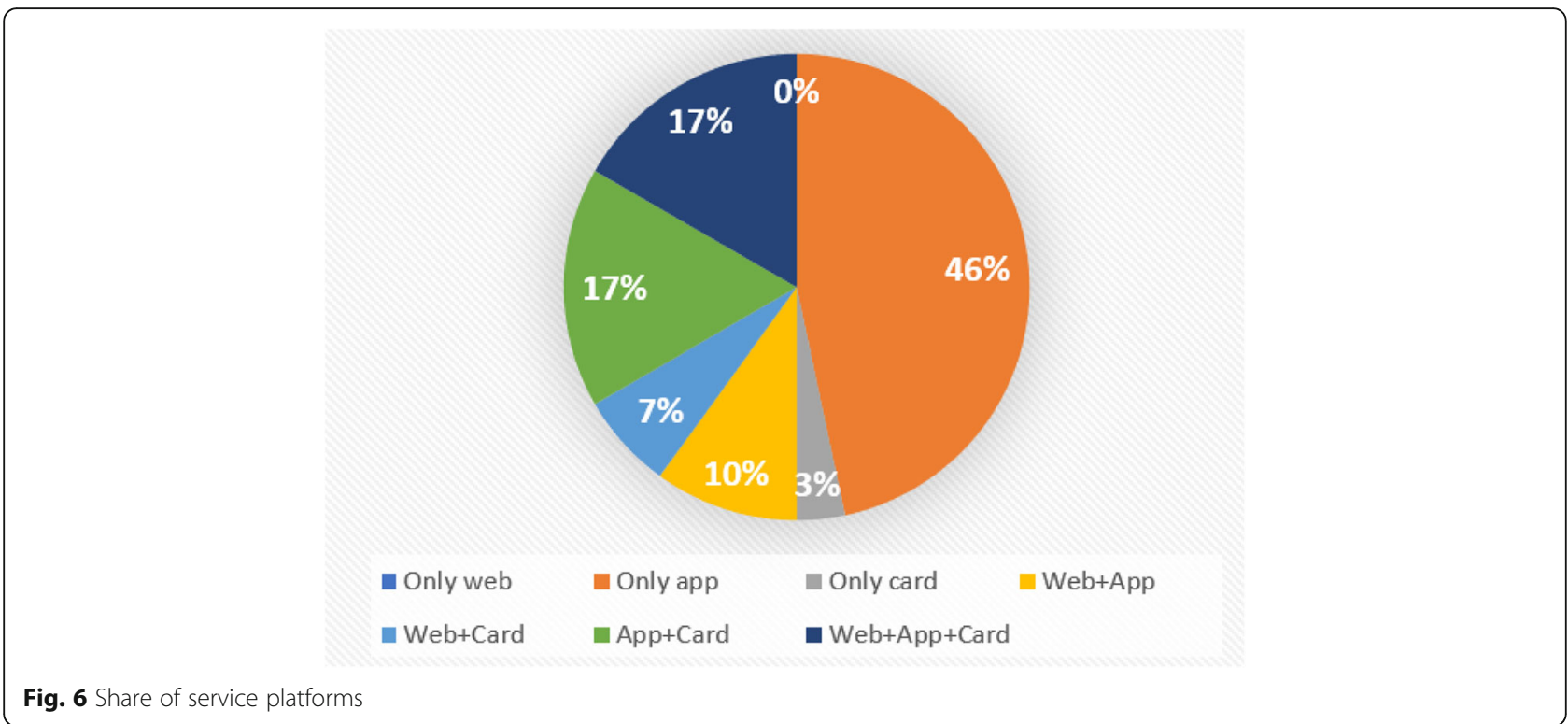

modes, stored trips, and saved locations, and three of them were less frequent including service alerts, route planning preferences, and traffic information. Saving locations and providing preferable transportation modes tended to occur together. Only in four cases were at least five features realized.

\subsection{Cluster analysis}

In the cluster analysis, the aim was to create typical clusters of MaaS services. Different cluster numbers from 1 to 10 were tried by using both the Elbow and the Silhouette method [15], and the most meaningful result was decided to group into three clusters.

The factoextra package [16] in $\mathrm{R}$ [26] implements Halt $=1-H$ as the definition of $\mathrm{H}$ required. The Halt =
0.278 showed that the applications were remarkably apt to be clustered. A shortlist of the most important features was created to run the clustering algorithm; in order to take into account all aspects, the Hopkins statistics results were even lower. Finally, the basic data, the covered area, the platforms, the type of operators, and the other services were considered for creating the clusters.

The silhouette plot showed an average value of 0.25 for the whole clustering, which was a moderately good result. However, in Fig. 9, it is depicted that several applications reached high values, and most of them were well categorized.

The three clusters created by the analysis had several similarities (Fig. 10).

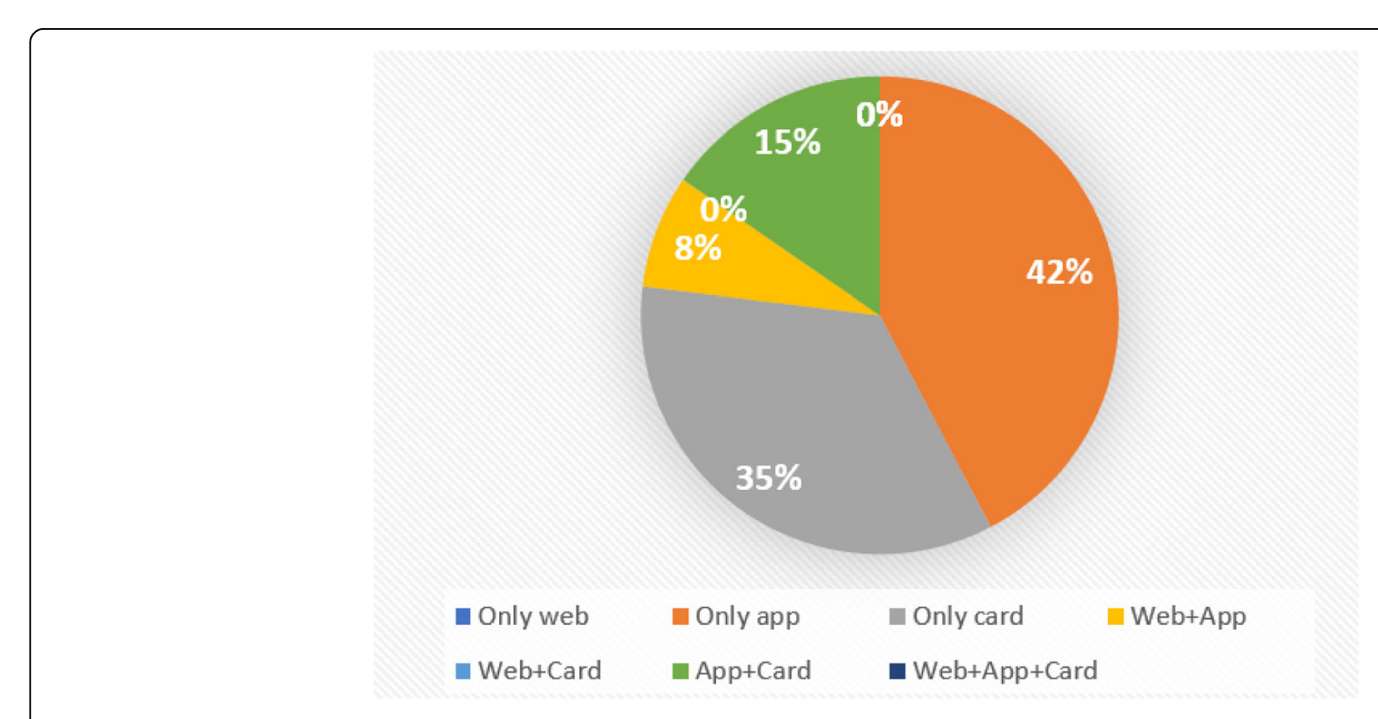

Fig. 7 Share of payment platforms 


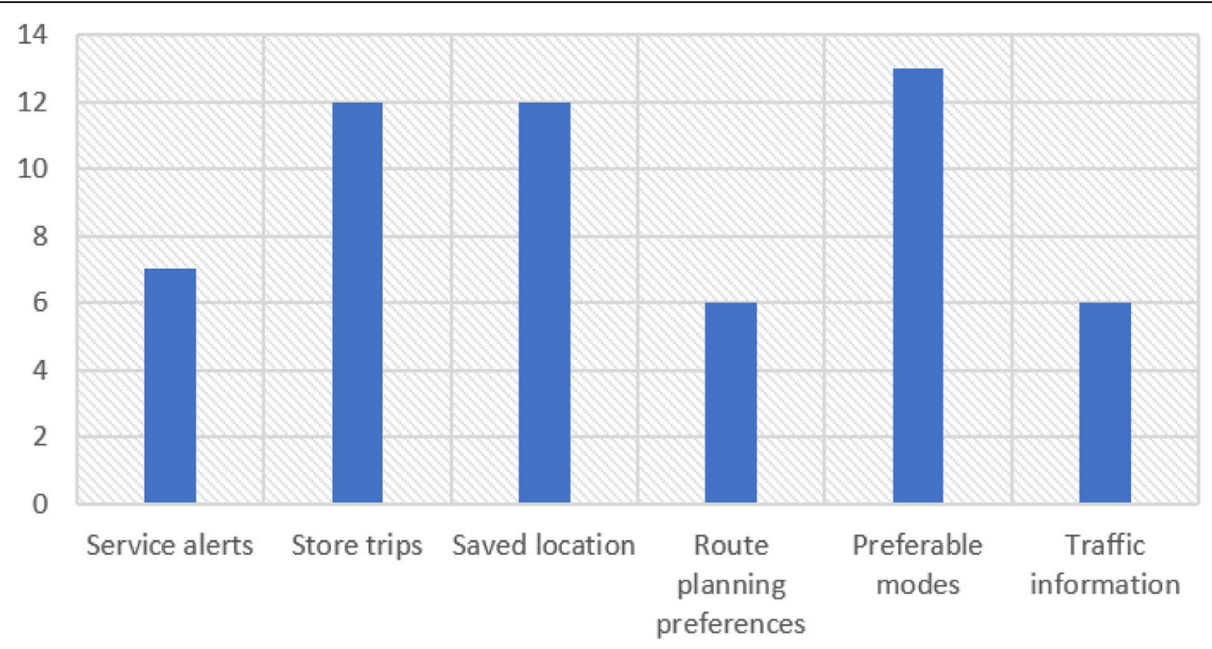

Fig. 8 Personalization and customization opportunities

In the first cluster group, called Route planners, solely route planning was integrated into the services, while payment was usually handled separately. This means that the payment solutions were not implemented in the applications, travel-related transactions could be made via a smart card. The scope of the service included a few transport modes, generally public transport, bicycles, car-sharing, and taxis.

The second group, called Third parties, was the most diverse considering most features of the services. Services ranging from non-payment to mobility packages were available. Their common feature was the third party involvement.

The third cluster, called Public systems, was characterized by the applications operated by public transport service providers or local authorities. As a result, these applications usually included ticketing for public transport, while other transportation modes may have required card usage, by any means, the user could get information on other transportation modes.

The three groups defined three distinct lines of development. The Route planners group involved a few modes of transport, but provided extensive service. The Third parties and the Public systems groups were divided into two separate types of MaaS operators: public (public transport operator) and private (third party).

\section{Discussion}

While several research works, pilot projects, commercial start-ups, and service extensions aimed to contribute to the MaaS paradigm, the market status was not analyzed in a comprehensive way. In this study, a data collection

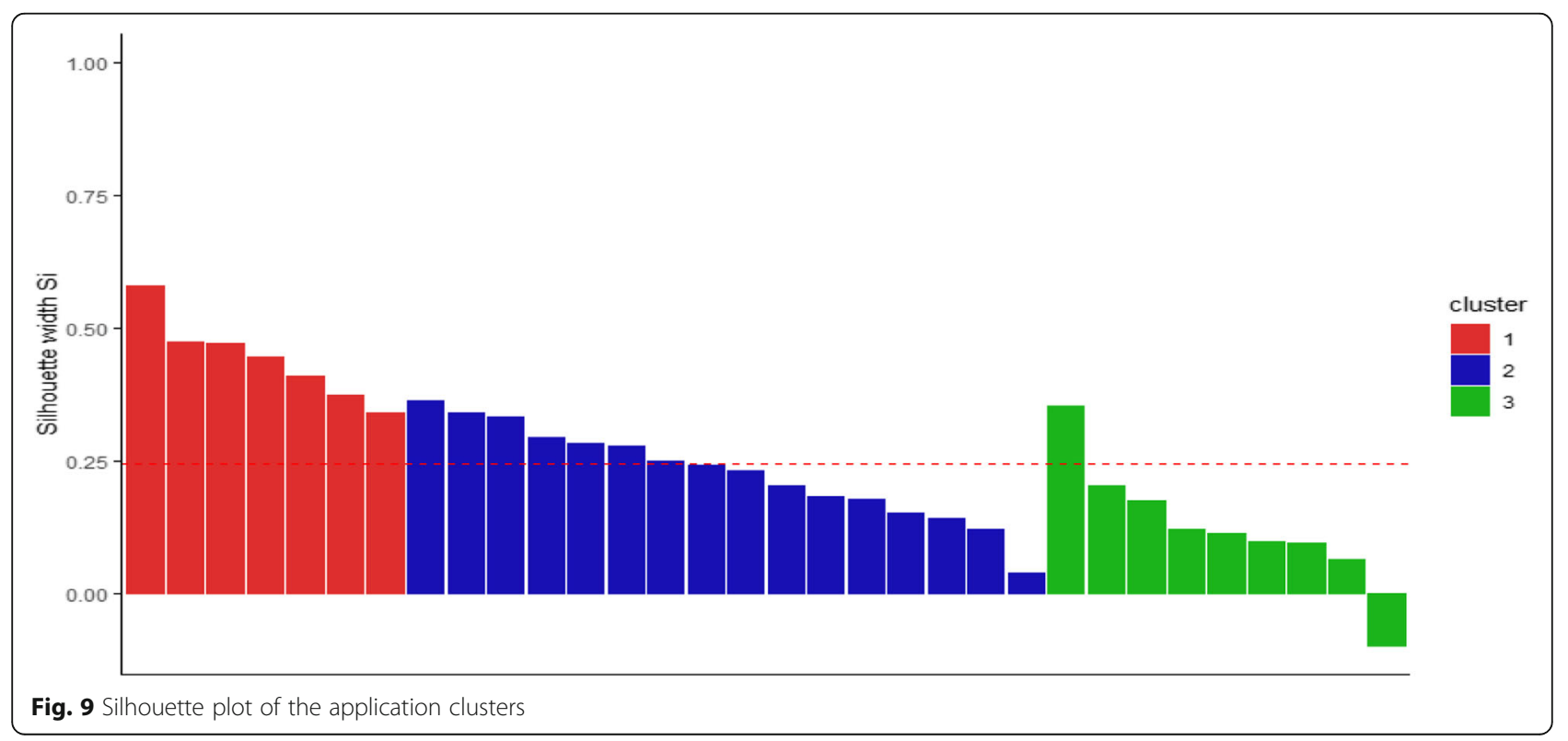




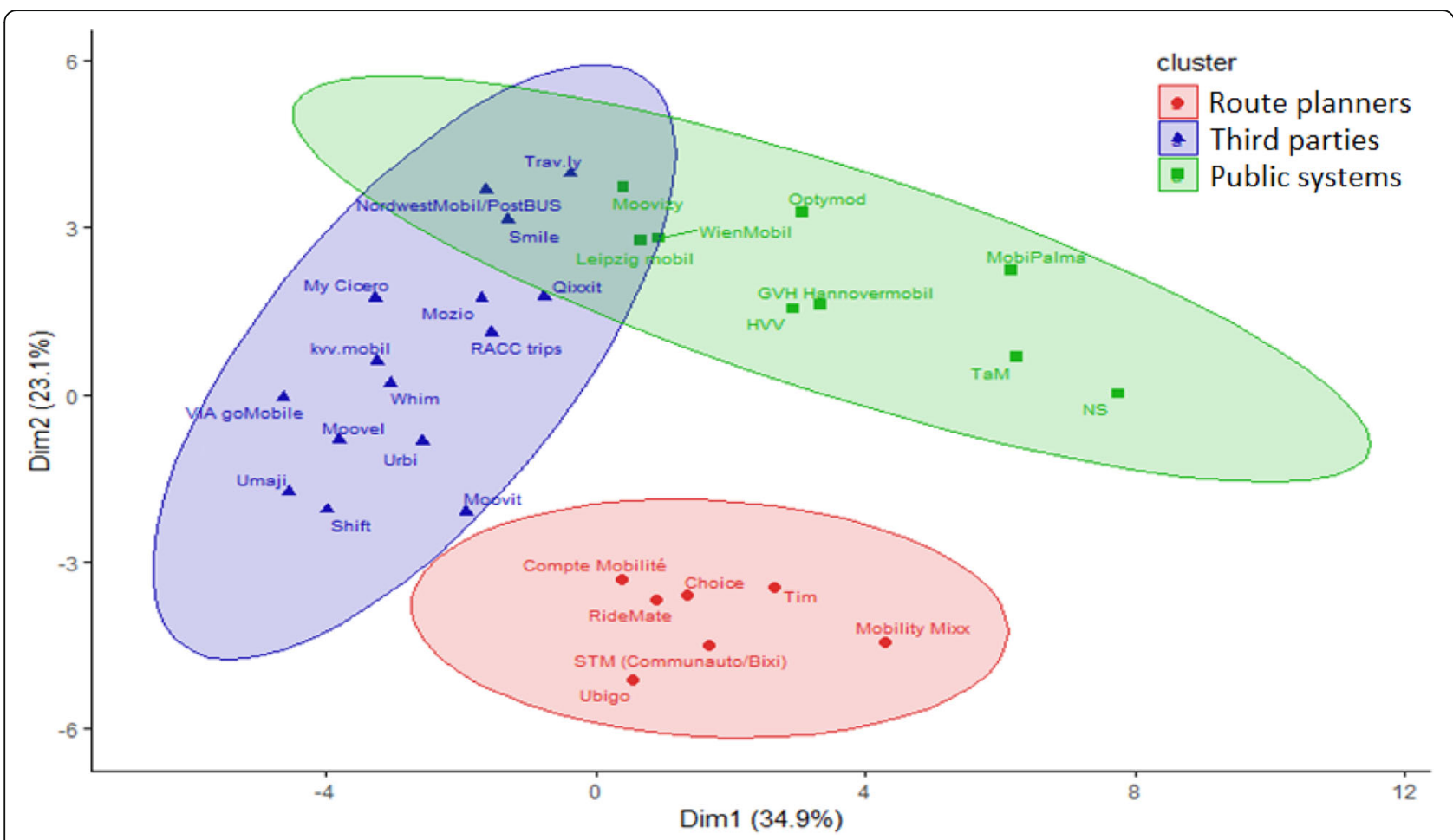

Fig. 10 Cluster plot of the three application clusters

methodology with explicit definitions was set up to create a consistent dataset. The current status of MaaS applications were demonstrated in the dataset, which might be used for further evaluations.

\subsection{General discussion}

Although only three initiatives had the highest level of integration, other projects included several important elements of the MaaS paradigm, as well. The majority of the examined MaaS initiatives were from Europe, but other regions had their first pioneers, too. The results showed some regional similarities, especially for German and Scandinavian areas.

Market growth might be foreseen from the results of this study. This means that new MaaS applications will be introduced in new service areas in the future. Interestingly, public transport was offered in only $70 \%$ of the studied cases. However, this value should have tended to reach $100 \%$ as public transport service is available almost everywhere; thus, it should have provided the backbone of a MaaS solution. This indicate that the public transport authorities shall be prepared for changes in the classical structure of the transportation market. Preparations should include not just the opening of passenger information and IT systems through application interfaces, but the harmonization of stakeholders' interest with the MaaS paradigm considering their business strategy.

\subsection{Business model validation}

UITP identified three business models for MaaS in their official report [37]: commercial integrator (Third parties), open back-end platform (Route planners) and transport as the integrator (Public Systems). In our research we proved that using cluster analysis, the applications can be grouped with high certainty according to the presented MaaS models.

The first business model is the "Route planners", which is a specific form as the service is run by the public transport operator without the support of external IT services. The operator encompasses other public or private transport operators and sets the rules for the operation. Thus, this business model provides no real opportunity for a competition, and data is not necessarily shared, too. Usually, the service represents a uni-city approach with a strong local basis. The main focus of the model is not on user-oriented and innovative services rather on social inclusion. Compte Mobilité is an example of this model, where the local public transport operator launched the application and invited other mobility operators. Compte Mobilités payment covers all modes of transport by a single settlement of the invoice at the end of the month. The application can be used with a card, which serves as a ticket, too. This service does not provide mobility packages either.

The second identified business model is the "Third parties", which is generally a multi-city approach with a 
strong IT basis based on the commercial agreements with the transport operators. The service appears in every city where there is interest and is commonly delivered by a third party operator. This business model creates a free market situation with clear competition and an opportunity for revenue generation. In general, data are not shared among the service providers; thus, information provision and social inclusion are not considered to a great extent. An example of this model is Whim, which develops its services in Helsinki, Antwerp, Amsterdam, and in the West-Midlands. Whim offers the same application for different cities. Therefore, it provides an interoperable system for the users. The Whim system is the application that is closest to the definition of the MaaS. Whim provides opportunities for routing, booking, ticketing, and paying for nearly all modes of transport, and travelers can choose a mobility package from three options. This service incorporates everything that the MaaS concept requires.

The third identified business model is the "Public systems" with an open back-end platform, which is typically set up by a national authority with internally determined rules. The platform serves an available infrastructure. Thus, the requirement for IT development is limited, but there is a compulsory data sharing among service providers. This business model allows competition only at the front end of the application. This version may offer more customer-oriented services, and local operators are more likely to be included. WienMobil is a good example, where Upstream Mobility, a subsidiary of Wiener Linien, set up a digital infrastructure to prepare access to local services and to make the market entry of the local MaaS operators possible. WienMobil is based on PT. In the system, payment options are available, but the booking option is missing from the provided services.

\subsection{Limitations}

The study is limited to analyze the offerings of the MaaS initiatives. A comprehensive market analysis should contain financial and economic performance as well as mobility-related examinations of the systems, too. Since MaaS solutions are in early stages, and in some cases, private investments are realized, the financial and economic performance of each service (e.g., revenues, profit, investment costs, or operational costs) is either unavailable or incomplete. Thus, this part is currently a limitation of the study.

Regarding the data, in this research, Google Play was used alone to assess the applications. The applications were checked on Google Play, using keywords, such as MaaS, mobility, transportation, and English language was applied. As Google Play provides reliable values, and to the current knowledge of the authors, there is no such comprehensive service which can measure the penetration of applications more exactly, the values of Google Play were used to compare the applications in terms of downloads. The research field might be extended to other online application stores, such as Apple App Store. However, currently Apple App Store does not provide information about the number of downloads. The number of downloads is a quantifiable and comparable number, which can be a suitable indicator. Unfortunately, there was no better and easier available method to capture the real penetration.

Another limitation of the study is that the collection of MaaS applications does not necessarily include all available services in the world, especially considering that new solutions appear every day. This research might not include certain systems which are out of the view of the authors; therefore, some quantitative results might be biased. A common problem of these kind of datadriven approaches is that an error in the data collection may cause problems in the understanding of the results. This was one of the reasons why a clustering method, which is less sensitive to outliers, was applied. At the same time, a cluster analysis is an unsupervised machine learning; thus, a proper interpretation of the results is necessary. This analysis should be considered as a review of the current status, and an overview of the majority of available MaaS applications.

In the future, the analysis might be extended with new participants from the market. Searching for new MaaS services and new MaaS operators might be conducted and the same process may be used with the above defined parameters. Special attention might be paid to cities or areas where two or more competitive MaaS services are available.

\section{Conclusions}

MaaS integrates different services, such as planning, booking, payment, and ticketing, via a single interface. The aim of this paper was to provide an overview of the currently available MaaS solutions, to analyze the features and the functionalities of the services, and to highlight the future development directions of the existing services. In order to compare these services, a database was developed taking into account the following parameters: the introduction date, the penetration rate, the area of coverage, the status, the included mobility services, the routing solutions, the booking solutions, the ticketing solutions, the payment solutions and platforms, the offered packages, the type of actors and operators, and other services.

The MaaS services were collected and analyzed based on their penetration, their area, and other aspects including the data from the applications, the web interfaces, and from the service provider's websites. 
Altogether, more than 30 initiatives from 14 countries were analyzed. Most of these schemes were from Europe, and a few were from North America, New Zealand, and Asia.

Considering the analysis, the number of operators is increasing by around four per year, there is a trend of a linear market growth. Moovit application operates in the most widely area and has the largest number of downloads, too. PostBus application handles the most modes of transport, and public transport is the most popular transportation mode. The most common form of MaaS operator is a third party structure, which is followed by public transport providers and local authorities. Most services are available via application; however, payment features are only available in less than $1 / 3$ of all operators. Only 10 of them are self-defined MaaS services, and only four of them provide the four elements: routing, booking, payment, and ticketing in one app. Around $50 \%$ of the MaaS services have a higher level of integration, but only three applications are fully integrated and offer mobility packages.

Based on the results of the cluster analysis, it can be observed that there are three cluster groups each with a distinct type of MaaS development. The Route planners' group involves a few modes of transport, but provides extensive route settings and route search service. While the services in the Third parties group have mainly private MaaS operators, those in the Public systems' group usually includes public MaaS operators. Based on the benchmarking of the MaaS market, three main business models were identified amongst MaaS operators. The Third parties usually appears in different cities and are typically run by a third party operator in a free market environment. The Public Systems solution is developed and regulated by the national authority; thus, it provides infrastructure, but also some constraints to the MaaS operators. While Route planners solutions are typically present in one city with a strong local basis without a competitive approach.

The MaaS market might be continuously extended. There are specific areas where competitive MaaS services mightbe available, which may create new business models for the operators and new opportunities for the users to choose the most suitable transport service. This comprehensive data collection and analysis supports current and potential MaaS operators and regulators in understanding typical features and development directions of the MaaS market.

\section{Acknowledgements}

The grammatical revision of this paper is prepared by Eszter Tóth.

\section{Authors' contributions}

Domokos Esztergár-Kiss: abstract, introduction, data analysis, conclusions. Tamás Kerényi: literature review, data collection and analysis, figures and tables. Tamás Mátrai: parameter definition, cluster analysis, language check.
Attila Aba: stakeholder analysis, parameter description, discussion. The authors read and approved the final manuscript.

\section{Funding}

The project has received funding from the European Union's Horizon 2020 research and innovation programme under grant agreement No 723176. The research reported in this paper was supported by the Higher Education Excellence Program in the frame of Artificial Intelligence research area of Budapest University of Technology and Economics (BME FIKP-MI/SC).

\section{Availability of data and materials}

The datasets used and/or analyzed during the current study are available from the corresponding author on reasonable request.

\section{Competing interests}

The authors declare that they have no competing interests.

Received: 7 April 2020 Accepted: 21 December 2020

Published online: 24 December 2020

\section{References}

1. Arnaoutaki, K., Magoutas, B., Bothos, E., \& Mentzas, G. (2019). A hybrid knowledge-based recommender for mobility-as-a-service. In Proceedings of the 16th International Joint Conference on e-Business and Telecommunications (ICETE 2019), (pp. 95-103). https://doi.org/10.5220/000792140095010.

2. Audouin, M., \& Finger, M. (2018). The development of mobility-as-a-service in the Helsinki metropolitan area: A multi-level governance analysis. Research in Transportation Business and Management, 27, 24-35. https://doi. org/10.1016/j.rtbm.2018.09.001.

3. Giesecke, R., Surakka, T., \& Hakonen, M. (2016). Conceptualising mobility as a service: A user centric view on key issues of mobility services. In Eleventh international conference on ecological vehicles and renewable energies, (pp. 68). IEEE, Monte Carlo. https://doi.org/10.1109/EVER.2016.7476443.

4. Goulding, R., \& Kamargianni, M. (2018). The mobility as a service maturity index: Preparing the cities for the mobility as a service era. In Proceedings of 7th transport research arena TRA 2018, (pp. 16-19). TRA, Vienna. https://doi. org/10.5281/zenodo.1485002.

5. Halkidi, M., Batistakis, Y., \& Vazirgiannis, M. (2001). On clustering validation techniques. Journal of Intelligent Information Systems, 17(2-3), 107-145.

6. Hensher, D., Mulley, C., Ho, C., Wong, Y., Smith, G., \& Nelson, J. (2020). Understanding mobility as a service (MaaS) - past, present and future. Elsevier, Amsterdam, The Netherlands. ISBN: 9780128200445.

7. Hietanen, S. (2014). Mobility as a service - The new transport model? ITS \& Transport Management Supplement - Eurotransport, 12(2), 2-4.

8. Holmberg, P-E., Collado, M., Sarasini, S., \& Williander, M. (2016). Mobility as a Service - MaaS describing the framework, final report maas framework. https://www.transport20.no/wp-content/uploads/2016/06/maas.pdf, Accessed: 01.06.2020.

9. IMOVE project (2017). https://www.imove-project.eu/, Accessed: 01.06.2020.

10. Jittrapirom, P., Caiati, V., Feneri, A.-M., Ebrahimigharehbaghi, S., AlonsoGonzález, M. J., \& Narayan, J. (2017). Mobility as a Service: A critical review of definitions, assessments of schemes, and key challenges. Urban Planning, 2(2), 13-25. https://doi.org/10.17645/up.v2i2.931.

11. Jittrapirom, P., Marchau, V. A. W. J., Heijen, R. E. C. M., \& Meurs, H. J. (2018). Future implementation of mobility as a Service (MaaS): Result of an international Delphi study. Travel Behaviour and Society. https://doi.org/10. 1016/j.tbs.2018.12.004.

12. Kamargianni, M., Li, W., \& Matyas, M. (2016). A critical review of new mobility services for urban transport. In 6th Transport Research Arena, (pp. 18-21). Transportation Research Procedia, Warsaw. 14, 3294-3303. https://doi.org/10. 1016/j.trpro.2016.05.277.

13. Kamargianni, M., \& Matyas, M. (2017). The business ecosystem of mobility as a service. In 96th Transportation Research Board (TRB) Annual Meeting, (pp. 8-12). Washington DC, Transportation Research Board.

14. Kamargianni, M., Matyas, M., Li, W., Muscat, J., \& Yfantis, L. (2018). The MaaS dictionary. In MaaSLab. Energy Institute, University College London. https:// www.maaslab.org. Accessed 01 June 2020.

15. Kassambara, A. (2017). Practical guide to cluster analysis in R: Unsupervised machine learning. In CreateSpace Independent Publishing Platform. Exeter: STHDA ISBN: 978-1542462709. 
16. Kassambara, A., \& Fabian, M., (2020). Factoextra: Extract and visualize the results of multivariate data analyses. https://rdrr.io/cran/factoextra/, Accessed: 01.06.2020.

17. Kaufman, L., \& Rousseeuw, P. J. (1990). Finding groups in data: An introduction to cluster analysis. Wiley series in probability and statistics. Hoboken: Wiley ISBN: 978-0471878766.

18. MaaS Alliance (2019). What is MaaS. Brussels: MaaS Alliance https://maasalliance.eu/homepage/what-is-maas/ Accessed: 01.06.2020.

19. MaaS4EU project (2017). http://www.maas4eu.eu/, Accessed: 01.06.2020.

20. MAASiFiE project (2015). https://www.vtt.fi/sites/maasifie, Accessed: 01.06. 2020.

21. Marco, B., Hans, A., Paola, C., Marco, G., \& Stefano, P. (2018). Unlocking large scale access to combined mobility through MaaS applications in Europe: the IMOVE approach. In Proceedings of 7th transport research arena TRA 2018, (pp. 16-19). TRA, Vienna. https://doi.org/10.5281/zenodo.1491599.

22. Mátrai, T., \& Tóth, J. (2016). Comparative assessment of public bike sharing system. Transportation Research Procedia, 14, 2344-2351. https://doi.org/10 1016/j.trpro.2016.05.261.

23. MyCorridor project (2017). https://www.iru.org/MyCorridor, Accessed: 01.06. 2020

24. New mobility project (2017). https://www.nymobilitet.dk/, Accessed: 01.06. 2020.

25. Pick\&Mix project (2017). https://gtr.ukri.org/projects?ref=102619, Accessed: 01.06.2020.

26. R Core Team (2020). R: A language and environment for statistical computing. https://www.r-project.org/, Accessed: 01.06.2020.

27. Saif, M., Zefreh, M., \& Torok, A. (2019). Public transport accessibility: A literature review. Periodica Polytechnica Transportation Engineering, 47(1), 3643. https://doi.org/10.3311/PPtr.12072.

28. Sarasini, S., Sochor, J., \& Arby, H. (2017). What characterises a sustainable MaaS business model. In 1st international conference on mobility as a service (ICOMaaS), (pp. 28-29). ICOMaaS, Tampere.

29. Schikofsky, J., Dannewald, T., \& Kowald, M. (2020). Exploring motivational mechanisms behind the intention to adopt mobility as a service (MaaS): Insights from Germany. Transportation Research Part A: Policy and Practice, 131, 296-312. https://doi.org/10.1016/j.tra.2019.09.022.

30. Smile project (2012). http://smile-einfachmobil.at/index_en.html, Accessed: 01.06.2020.

31. Smith, G., Sochor, J., \& Karlsson, I. C. M. (2018). Mobility as a service: Development scenarios and implications for public transport. Research in Transportation Economics, 69, 592-599. https://doi.org/10.1016/j.retrec.2018. 04.001.

32. Sochor, J., Arby, H., \& Karlsson, M. (2017). The topology of mobility as a service: A tool for understanding effects on business and society, user behavior, and technological requirements. In 24th World Congress on Intelligent Transportation Systems. Montreal: 29 October - 2 November 2017. ITS World

33. Sochor, J., Arby, H., Karlsson, M., \& Sarasini, S. (2018). A topological approach to mobility as a service: A proposed tool for understanding requirements and effects, and for aiding the integration of societal goals. Research in Transportation Business \& Management, 27, 3-14. https://doi.org/10.1016/j. rtbm.2018.12.003.

34. Stopka, U., Peisser, R., \& Günther, K. (2018). Mobility as a service (MaaS) based on intermodal electronic platforms in public transport. HumanComputer Interaction ( $\mathrm{HCl}$ 2018). In Lecture Notes in Computer Science, (vol. 10902, pp. 419-439). Cham: Springer. https://doi.org/10.1007/978-3-31991244-8_34

35. Ubigo project (2012). https://www.mistraurbanfutures.org/en/project/ gosmart, Accessed: 01.06.2020.

36. UITP. (2011). Becoming a real mobility provider combined mobility, position paper, http://www.uitp.org/sites/default/files/cck-focus-papers-files/ FPComMob-en.pdf, Accessed: 01.06.2020.

37. UITP (2019). Mobility as a Service, report, https://cms.uitp.org/wp/wpcontent/uploads/2020/07/Report_MaaS_final.pdf, Accessed: 01.06.2020.

38. Utriainen, R., \& Pöllänen, M. (2018). Review on mobility as a service in scientific literature. Research in Transportation Business \& Management, 27, 15-23. https://doi.org/10.1016/j.rtbm.2018.10.005.

\section{Publisher's Note}

Springer Nature remains neutral with regard to jurisdictional claims in published maps and institutional affiliations.

\section{Submit your manuscript to a SpringerOpen ${ }^{\circ}$ journal and benefit from:}

- Convenient online submission

- Rigorous peer review

- Open access: articles freely available online

High visibility within the field

- Retaining the copyright to your article

Submit your next manuscript at $\boldsymbol{\nabla}$ springeropen.com 